\title{
Corrosion Behavior of Alumina Reinforced Aluminium (6063) Metal Matrix Composites
}

\author{
K. K. Alaneme* and M. O. Bodunrin \\ Department of Metallurgical and Materials Engineering, Federal University of Technology, \\ Akure, Nigeria \\ *Corresponding Author: kalanemek@yahoo.co.uk
}

\begin{abstract}
The influence of alumina volume percent and solution heat-treatment on the corrosion behaviour of Al (6063) composites and its monolithic alloy in salt water, basic and acidic environments is investigated. $\mathrm{Al}$ (6063) $-\mathrm{Al}_{2} \mathrm{O}_{3}$ particulate composites containing 6, 9, 15, and 18 volume percent alumina were produced by adopting two step stir casting. Mass loss and corrosion rate measurements were utilized as criteria for evaluating the corrosion behaviour of the composites. It is observed that $\mathrm{Al}(6063)-\mathrm{Al}_{2} \mathrm{O}_{3}$ composites exhibited excellent corrosion resistance in $\mathrm{NaCl}$ medium than in the $\mathrm{NaOH}$ and $\mathrm{H}_{2} \mathrm{SO}_{4}$ media. The unreinforced alloy exhibited slightly superior corrosion resistance than the composites in $\mathrm{NaCl}$ and $\mathrm{NaOH}$ media but the composites had better corrosion resistance in $\mathrm{H}_{2} \mathrm{SO}_{4}$ medium. Furthermore, solution heat-treatment resulted in improved corrosion resistance for both the composites and the unreinforced alloy while the effect of volume percent alumina on corrosion resistance did not follow a consistent trend.
\end{abstract}

Keywords: Stir casting; $\mathrm{Al}(6063)-\mathrm{Al}_{2} \mathrm{O}_{3}$ composite; solution heat-treatment; Corrosion rate; mass loss

\section{INTRODUCTION}

The development of $\mathrm{Al}$ based metal matrix composites is attracting a lot of interest from materials engineers in developing countries [1]. This interest spans from the low cost of aluminium based alloys in comparison with other potential metal matrices and the wide spectrum of properties it offers which includes: high specific strength and stiffness, improved high temperature properties, controlled thermal expansion coefficient, improved wear and abrasion resistance among others [2 - 4]. Most research works on Al based matrix composites found in literature have been based on the $2 \mathrm{XXX}$ and $6 \mathrm{XXX}$ series. The $6 \mathrm{XXX}$ series of Al-Mg- Si alloys are widely used as medium strength structural alloys which have the advantages of good weldability, corrosion resistance, and immunity to stress corrosion cracking [5 - 6]. However, very little has been reported on the use of $\mathrm{Al}$ (6063) alloy as metal matrix [6]. Al (6063) alloy happens to be processed in large quantities at low cost in most developing countries which 
informs the current interest in its viability for the development of $\mathrm{Al}$ based metal matrix particulate composites. Considerations of the mechanical properties of Al (6063) matrix composites have received some attention [1] but information on its corrosion characteristics in typical industrial environments (such as acidic, marine and alkaline environments) is hardly available in literature. In the current work, the corrosion behaviour of alumina reinforced $\mathrm{Al}$ (6063) matrix composites produced using two - step stir casting process is investigated. Stir casting was selected because it is a cheap and efficient process route which also has the advantage of adaptability to the use of improvised facilities [7 - 9]. The investigation is intended to assess the corrosion resistance of the alumina reinforced Al (6063) matrix composites in acidic, salt water, and basic environments which are representative of typical service / industrial processing atmospheres [10].

\section{MATERIALS AND METHOD}

\subsection{Materials}

The materials utilized in the present study are 100 percent chemically pure alumina $\left(\mathrm{Al}_{2} \mathrm{O}_{3}\right)$ particles having particle size of $28 \mu \mathrm{m}$ and Aluminium 6063 alloy which served as the matrix. The composition of the Aluminium 6063 alloy is shown in Table 1.

Table 1. Chemical Composition of Aluminium 6063 Alloy

\begin{tabular}{|c|c|c|c|c|c|c|c|c|}
\hline $\mathrm{Si}$ & $\mathrm{Fe}$ & $\mathrm{Cu}$ & $\mathrm{Mn}$ & $\mathrm{Mg}$ & $\mathrm{Zn}$ & $\mathrm{Cr}$ & $\mathrm{Ti}$ & $\mathrm{Al}$ \\
\hline 0.45 & 0.22 & 0.02 & 0.03 & 0.50 & 0.02 & 0.03 & 0.02 & Bal. \\
\hline
\end{tabular}

\subsection{Stir Casting}

Aluminium (6063) alloy and $\mathrm{Al}_{2} \mathrm{O}_{3}$ particles required to produce the composites having 6,9, 15, and 18 volume percent alumina were determined by charge calculations. The alumina particles were initially preheated at a temperature of $250^{\circ} \mathrm{C}$ for 5 minutes to help improve wettability with the $\mathrm{Al}$ (6063) alloy. The $\mathrm{Al}$ (6063) alloy ingots were charged into a gas-fired crucible furnace and heated to a temperature of $750^{\circ} \mathrm{C} \pm 30^{\circ} \mathrm{C}$ (above the liquidus temperature of the alloy) and the liquid alloy was then allowed to cool in the furnace to a semi solid state at a temperature of about $600^{\circ} \mathrm{C}$. The preheated alumina was added at this temperature and stirring of the slurry was performed manually for 5 minutes. The composite slurry was then superheated to $720^{\circ} \mathrm{C}$ and a second stirring performed using a mechanical stirrer. The stirring operation was performed at a speed of 300rpm for 10minutes to help improve the distribution of the alumina particles in the molten Al (6063) alloy. The molten composite was then cast into prepared sand moulds. Al (6063) alloy without reinforcement was also prepared for control experimentation.

\subsection{Solution Heat-treatment}

Two different temper conditions were utilized in this study, the as-cast condition, and solution heat-treated condition. The solution heat-treatment was performed by solutionizing the samples at $550^{\circ} \mathrm{C}$ for 4 hours and then quenching in water. 


\subsection{Solution Preparation}

An aggressive marine environment was simulated by preparing $3.5 \mathrm{wt} \% \mathrm{NaCl}$ solution which is in accordance with Yussof et al [11]. The solution was prepared by dissolving 210grams of solid $\mathrm{NaCl}$ in $6000 \mathrm{~cm}^{3}$ of de-ionized water. $0.3 \mathrm{MH}_{2} \mathrm{SO}_{4}$ solution $(\mathrm{pH} 0.9$ ) was utilized as representative of an acidic environment. The $0.3 \mathrm{MH}_{2} \mathrm{SO}_{4}$ solution was prepared by adding $97.8 \mathrm{~cm}^{3}$ of concentrated $\mathrm{H}_{2} \mathrm{SO}_{4}$ with specific density of 1.84 and $98 \%$ purity to $6000 \mathrm{~cm}^{3}$ of deionized water. A basic environment of $0.1 \mathrm{M}$ of $\mathrm{NaOH}$ solution was also prepared by dissolving 24 grams of solid $\mathrm{NaOH}$ in $6000 \mathrm{~cm}^{3}$ of de-ionized water.

\subsection{Immersion Test}

The corrosion tests were carried out in $3.5 \mathrm{wt} \% \mathrm{NaCl}(\mathrm{pH} 7.4), 0.3 \mathrm{M} \mathrm{H}_{2} \mathrm{SO}_{4}(\mathrm{pH} 0.9)$, and $0.1 \mathrm{M}$ $\mathrm{NaOH}(\mathrm{pH} 12.7)$ solutions which were prepared following standard procedures. The specimens for the test were cut to size $20 \square \times \square 20 \square \times \square 5 \square \mathrm{mm}$, after which the sample surfaces were mechanically polished with emery papers starting from 120grit down to 640grit size. The samples were de-greased with acetone and then rinsed in distilled water before immersion in the prepared still solutions of $3.5 \mathrm{wt} \% \mathrm{NaCl}, 0.3 \mathrm{M} \mathrm{H}_{2} \mathrm{SO}_{4}$, and $0.1 \mathrm{M} \mathrm{NaOH}$; which were all exposed to atmospheric air. The solution-to-specimen surface area ratio was about $150 \mathrm{ml} \mathrm{cm}$. The results of the corrosion tests were evaluated by mass loss and corrosion rate measurements on two day intervals. The samples were exposed in the acidic, basic and alkaline environments for 40, 29 and 45 days respectively. Mass loss $\left(\mathrm{mg} / \mathrm{cm}^{2}\right)$ for each sample was evaluated by dividing the weight loss (measured using a four decimal digit electronic weighing balance) by its total surface area which is in accordance with ASTM standard recommended practice ASTM G31 [12]. Corrosion rate for each sample was evaluated from the weight loss measurements following standard procedures.

\section{RESULTS AND DISCUSSION}

\subsection{Corrosion Behaviour in 3.5wt\% NaCl Solution}

Figure 1 and 2 presents the mass loss and corrosion rate plots for the as - cast and solution heattreated samples immersed in the $3.5 \mathrm{wt} \% \mathrm{NaCl}$ solution. It is observed from Figure 1 that the corrosion rate of both the unreinforced alloy and the alumina reinforced composites in the as-cast condition were generally very low (less than $0.1 \mathrm{mmpy}$ ). This is an indication that the passive films formed on the surface of both the unreinforced alloy and the composites are stable and immune to attack when immersed in $3.5 \mathrm{wt} \% \mathrm{NaCl}$ environment. This is a clear indication that the composites will be suitable for use in marine environments. The mass loss profiles (Figure 1b) however show that the composites have slightly inferior resistance to corrosion (as reflected by the relatively lower weight gain values) in comparison with the unreinforced alloy. Zhu and Hihara [13] have confirmed similar trend in alumina fiber reinforced Al composites; and attributed it to be due to the preferential initiation of corrosion in the alumina/Al matrix interface. The influence of alumina volume percent on the corrosion characteristics was not apparent as the composites exhibited almost the same level of resistance to corrosion. 
Solution heat-treatment (Figure 2) is observed to result in a slight improvement in corrosion resistance of the composites particularly for the 15 and 18 volume percent alumina reinforcement in comparison with the as-cast composites (Figure 1). The slight improvement in corrosion resistance can be attributed to the improved dispersion of the alumina particles in the $\mathrm{Al}$ (6063) matrix and the dissolution of second phase particles in the unreinforced alloy [14].

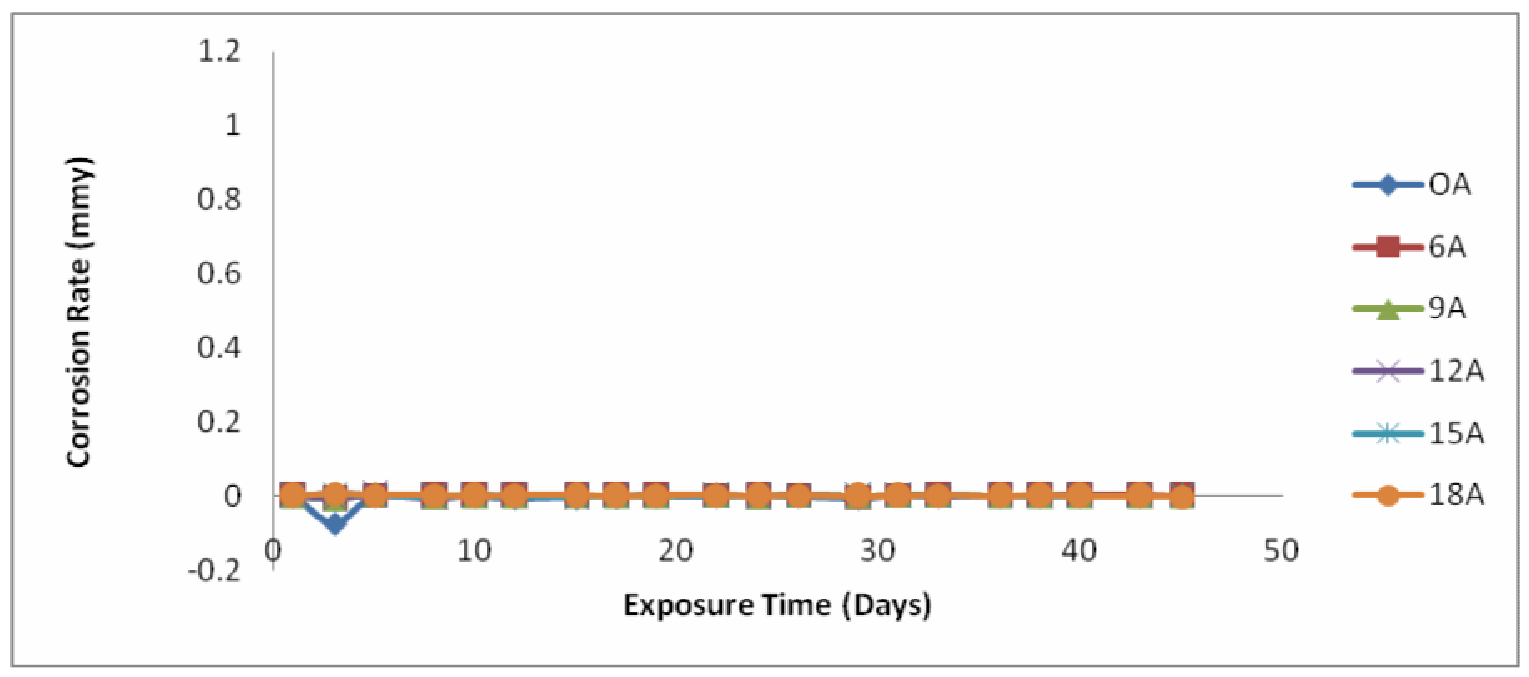

Figure 1a- Variation of corrosion rate of as-cast samples in 3.5\% $\mathrm{NaCl}$

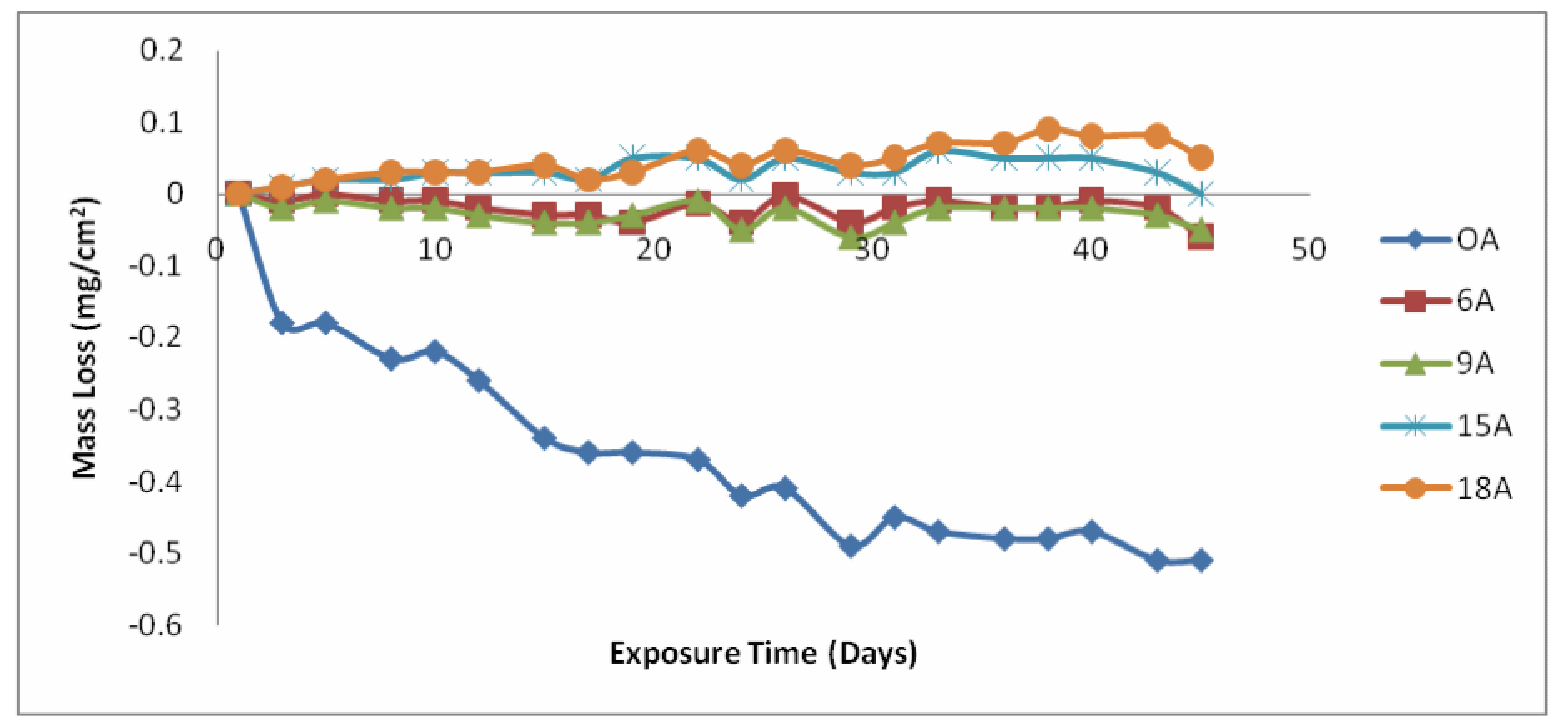

Figure 1b- Variation of mass loss of as-cast samples in $3.5 \% \mathrm{NaCl}$ 


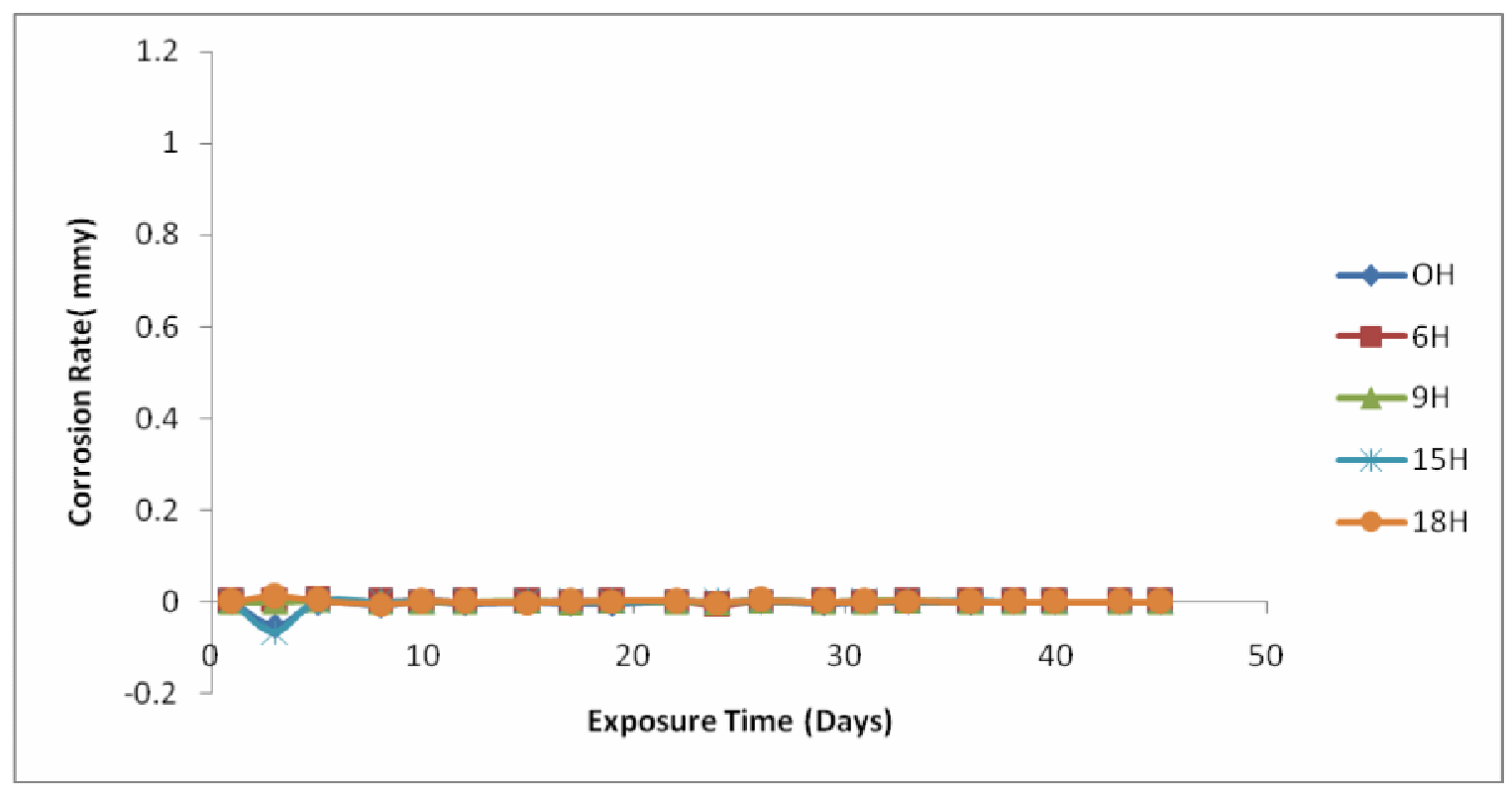

Figure 2a- Variation of corrosion rate of solution-heat treated samples in $3.5 \% \mathrm{NaCl}$

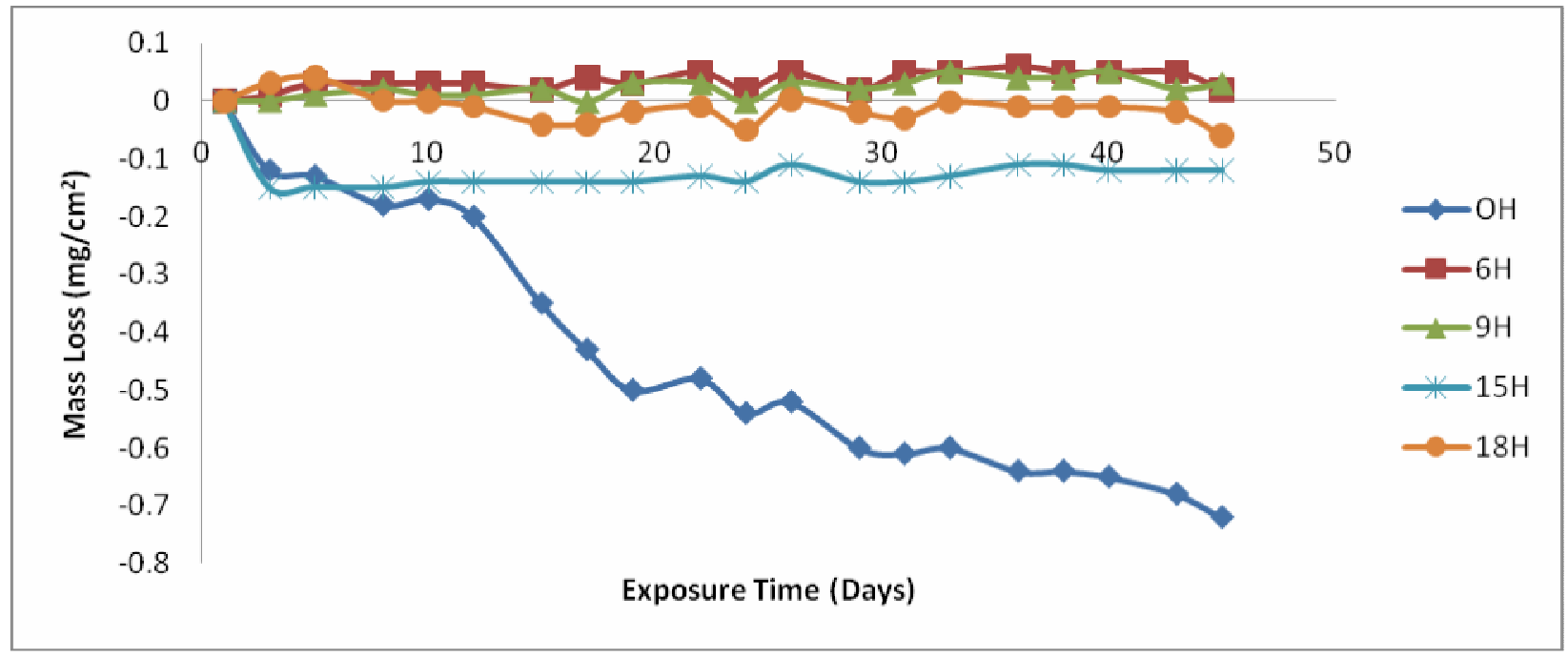

Figure 2b- Variation of mass loss of solution-heat treated samples in $3.5 \% \mathrm{NaCl}$

\subsection{Corrosion Behaviour in 0.1M NaOH Solution}

Figure 3 and 4 presents the mass loss and corrosion rate plots for the as-cast and solution heattreated samples immersed in $0.1 \mathrm{MNaOH}$ solution. It is observed from Figure 3(a) that the corrosion rate was only intense for the first three days of immersion for all the samples (unreinforced alloy and the composites), after which there was a drastic drop in the corrosion rate which was maintained for the rest of the immersion period. The mass loss plots (Figure $3 b$ ) reveal that for the composites, corrosion susceptibility was highest for the 9 volume percent alumina reinforcement. This could be due to segregation of alumina particles in the matrix which 
is very common in as-cast composites, and promotes nucleation of pits which facilitates corrosion [15]. Kolman and Butt [16] reported that surface variations due to the presence of ceramic reinforcement in the matrix can also promote film flaws and hence increase pitting. However, it is observed that the 6 and 18 volume percent alumina reinforcement had lower mass loss in comparison to the unreinforced alloy.

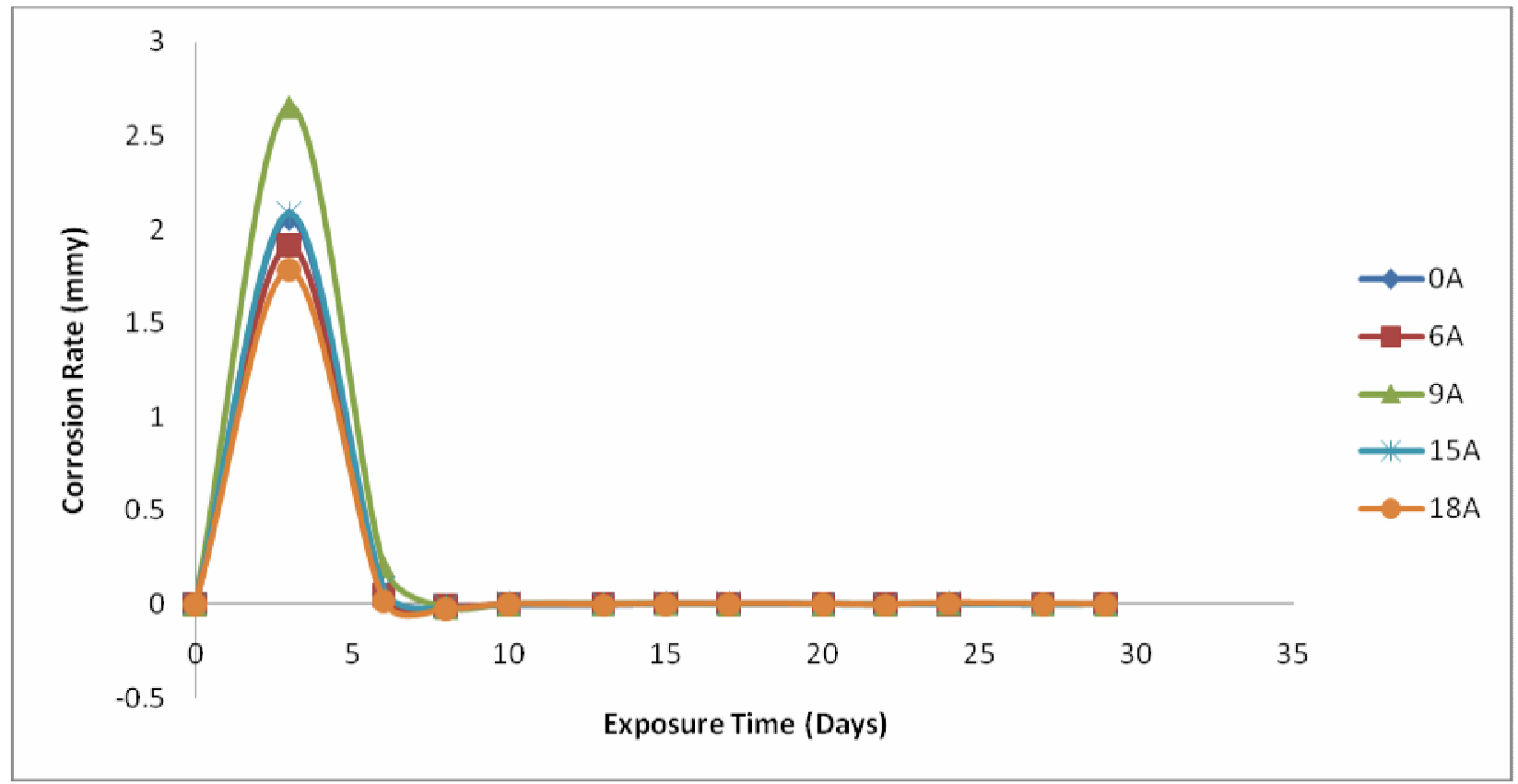

Figure 3a- Variation of corrosion rate against exposure time of as-cast samples in $\mathrm{NaOH}$

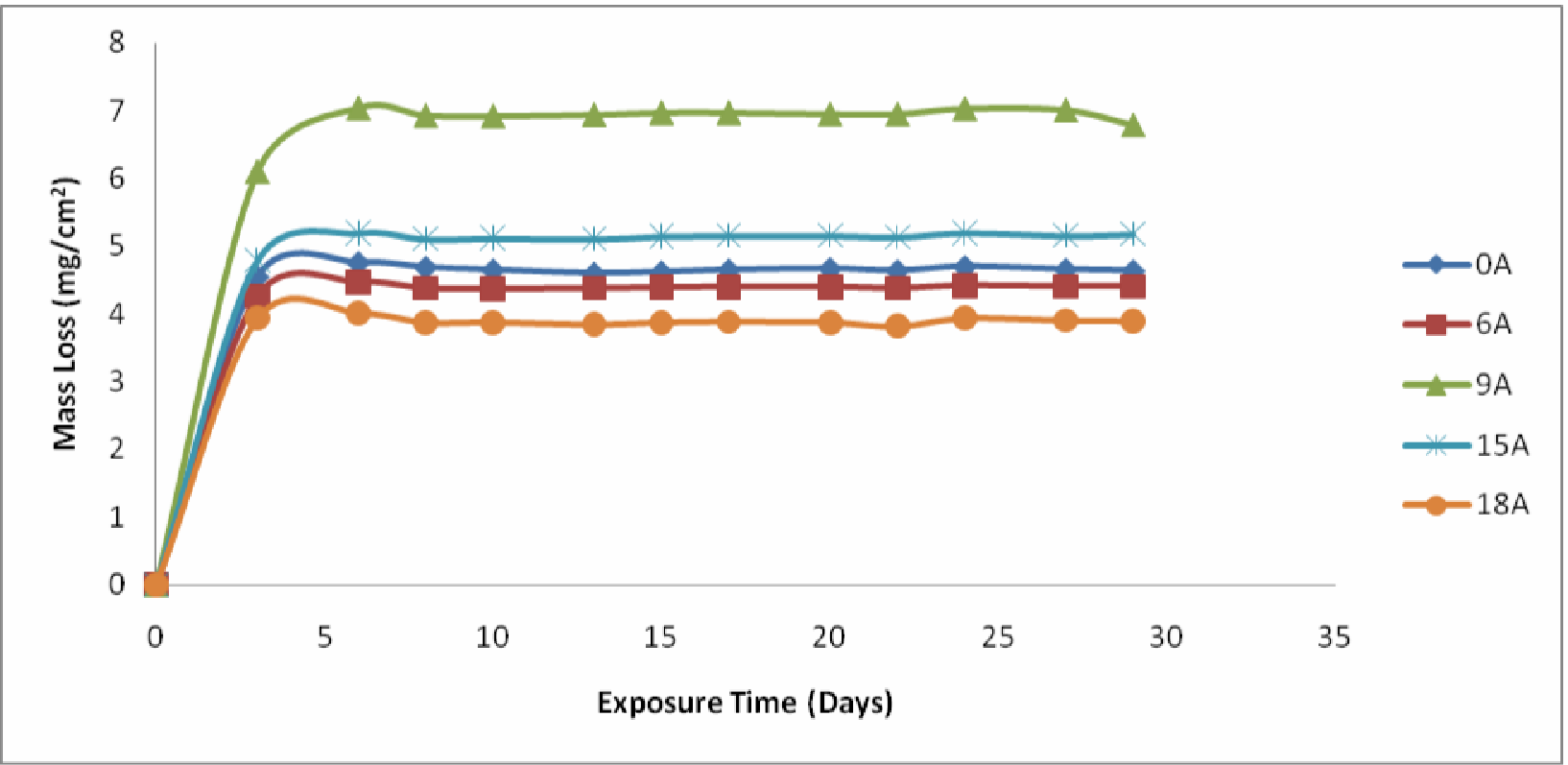

Figure 3b- Variation of mass loss against exposure time of as-cast samples in $\mathrm{NaOH}$ 


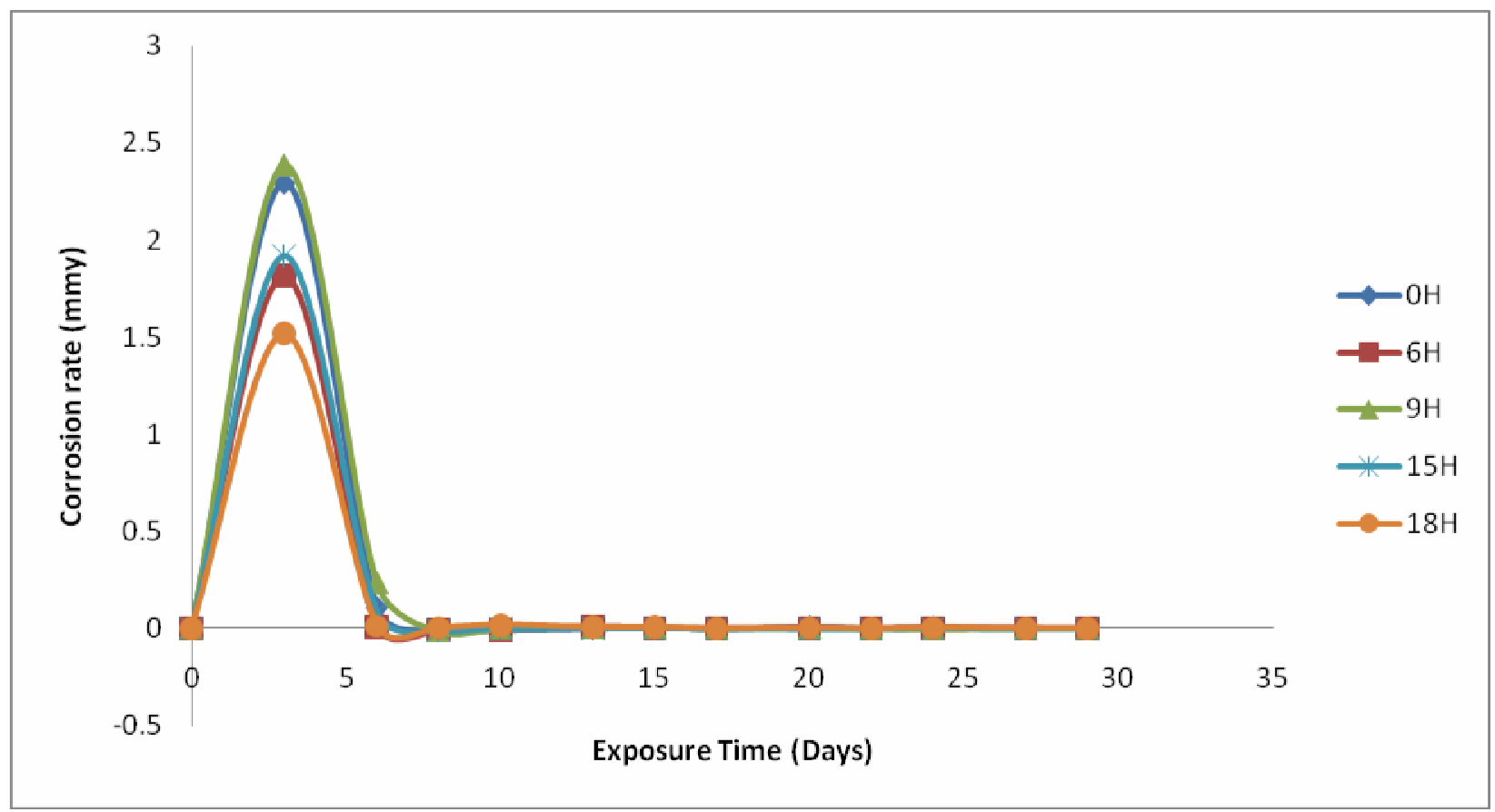

Figure 4a- Variation of corrosion rate of solution-heat treated samples in $\mathrm{NaOH}$

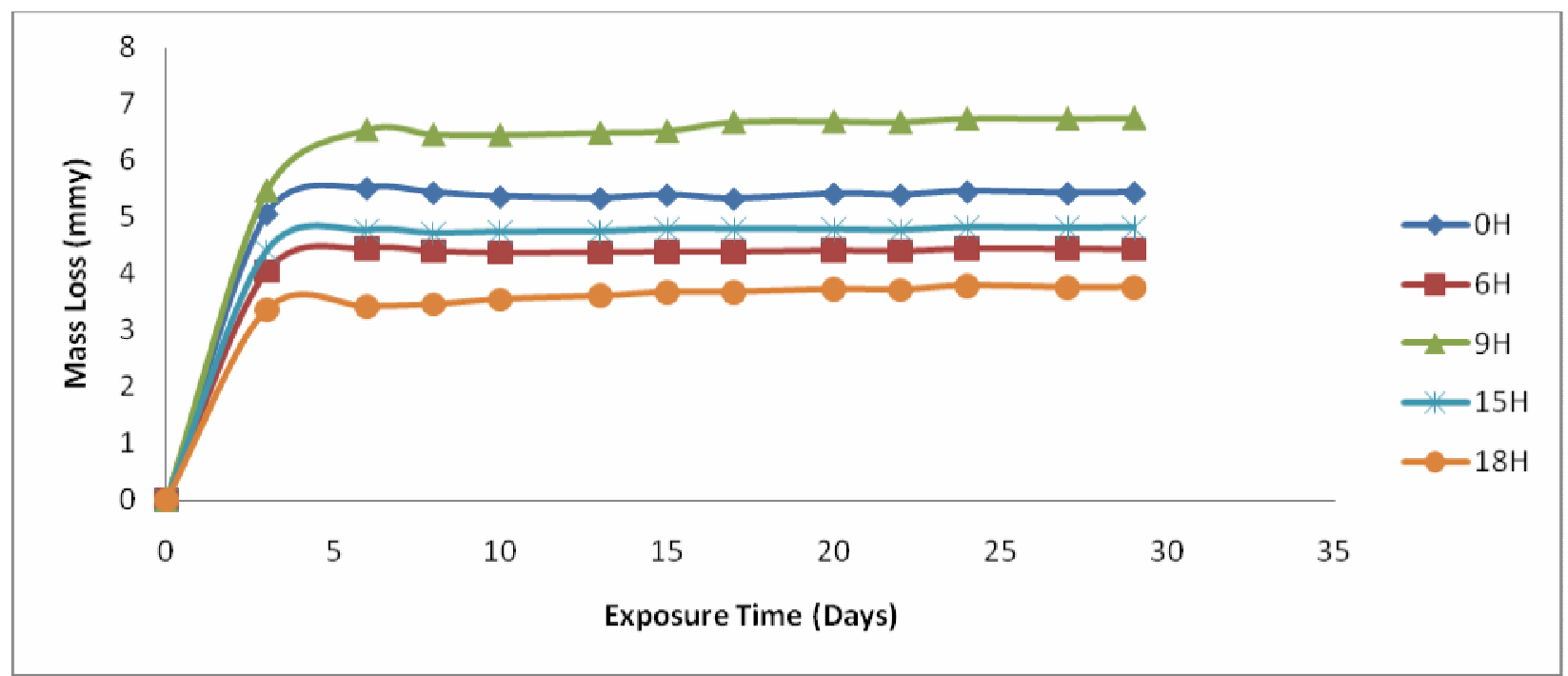

Figure 4b- Variation of mass loss of solution-heat treated samples in $\mathrm{NaOH}$

Solution heat-treatment (Figure 4) resulted in a slight reduction in corrosion rate and mass loss for all volume percent of the alumina reinforced composite in comparison with the as-cast samples (Figure 3). The slightly improved corrosion resistance is ascribed to improved distribution of the alumina particles in the Al (6063) matrix [14]. For both the as-cast and solution heat-treated samples, it was observed that a black film was formed on the surface of the samples (Figure 5). Similar black film formation has been observed in AMCs reinforced with 
alumina and zircon [17-18]. They both observed that the formation of the black film (which contains hydroxyl chloride) mitigated the corrosion of the composites.

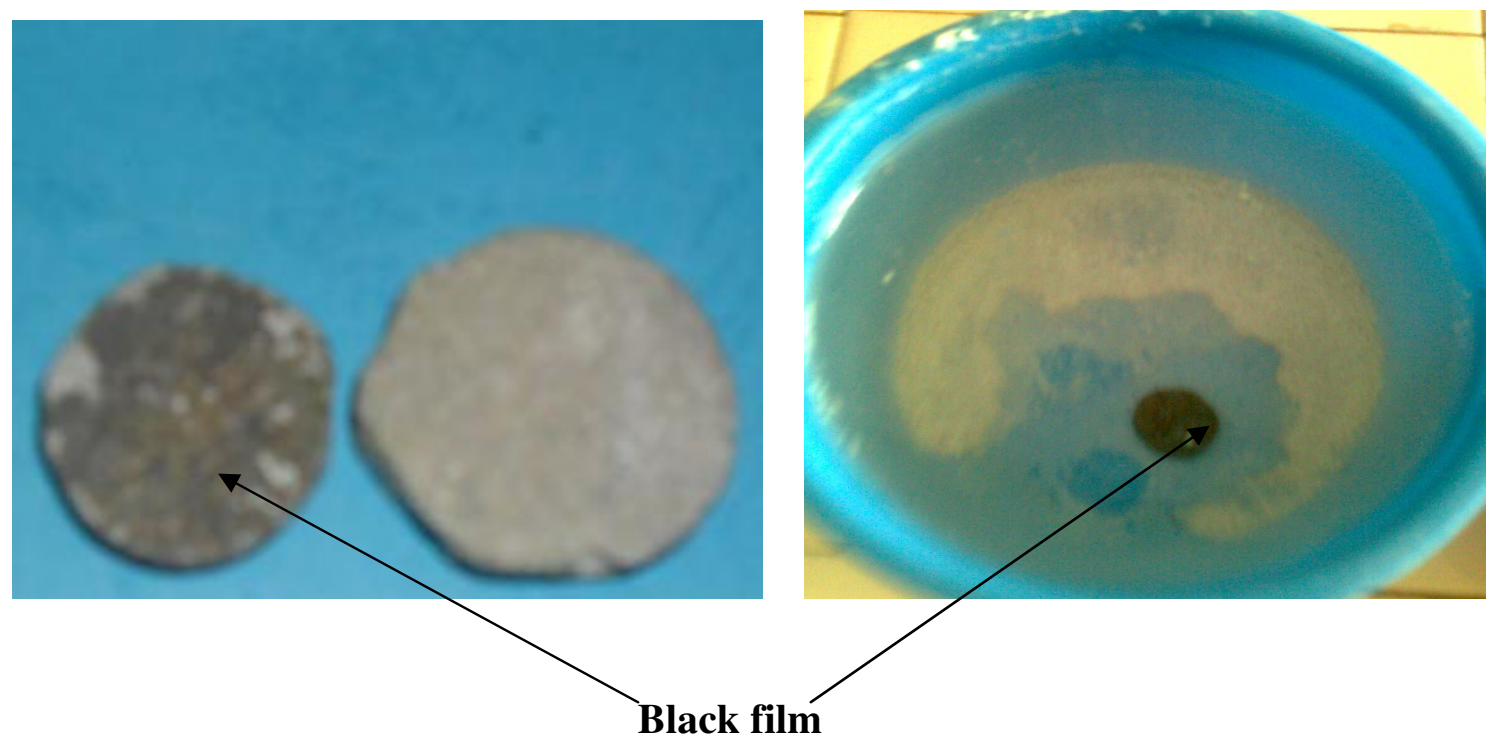

Figure 5:Black film on the surface of the composite retarding corrosion rate in $\mathrm{NaOH}$.

\subsection{Corrosion Behaviour in $\mathrm{0.3M} \mathrm{H}_{2} \mathrm{SO}_{4}$ Solution}

Figure 6 and 7 show the plots of corrosion rate and mass loss for the as-cast and solution heattreated samples immersed in $0.3 \mathrm{M} \mathrm{H}_{2} \mathrm{SO}_{4}$ solution. The corrosion rate curves (Figure 6a and 7a) reveal that the passive films formed on the specimens for both the as-cast and solution heat-treated conditions were not stable as there was repeated film formation (reflected by a low corrosion rate) and breakdown (reflected by an increase in corrosion rate) in the course of exposure in $0.3 \mathrm{M} \mathrm{H}_{2} \mathrm{SO}_{4}$ solution. The mass loss plots (Figure $6 \mathrm{~b}$ and $7 \mathrm{~b}$ ) indicate that there is a high rate of dissolution of the samples in $0.3 \mathrm{M} \mathrm{H}_{2} \mathrm{SO}_{4}$ solution in comparison with $3.5 \mathrm{wt} \% \mathrm{NaCl}$ (Figure $1 \mathrm{~b}$ and $2 \mathrm{~b}$ ) and $0.1 \mathrm{M}$ $\mathrm{NaOH}$ (Figure $3 \mathrm{~b}$ and $4 \mathrm{~b}$ ). Figure 8 show that the corrosion mechanism is pitting corrosion which is in agreement with the observations of Hihara [19].

The composites however, had better resistance to corrosion in $0.3 \mathrm{M} \mathrm{H}_{2} \mathrm{SO}_{4}$ solution in comparison to the unreinforced alloy, as reflected by the lower mass loss of the composites in both the as-cast and the solution heat-treated condition (Figure 6b and 7b). Zuhair and Al-Qutub [20] reported that increase in alumina volume fraction in $\mathrm{Al} 6061 / \mathrm{Al}_{2} \mathrm{O}_{3 p}$ composites delayed pitting and resulted in the formation of numerous but shallow pits. The solution heat-treatment is observed to reduce the mass loss of the composites particularly for the 18 volume percent alumina reinforced composite where mass loss of $17 \mathrm{mg} / \mathrm{cm}^{2}$ in the as-cast condition reduced to $6.5 \mathrm{mg} / \mathrm{cm}^{2}$ for the solution heat-treated condition. This is attributed to the even distribution of the particles in the matrix as a result of the solution heat-treatment [21]. 


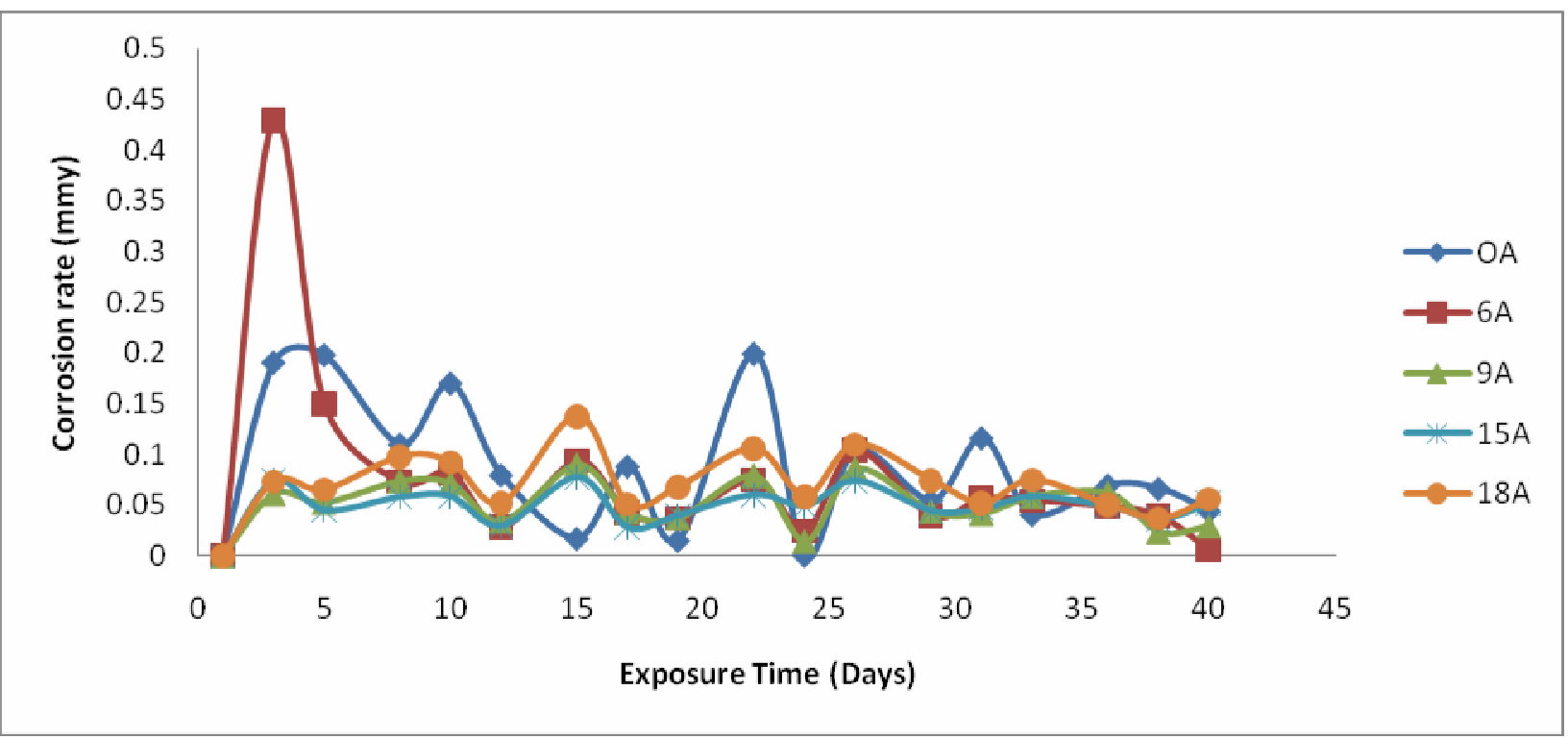

Figure 6a- Variation of corrosion rate of as-cast samples in $\mathrm{H}_{2} \mathrm{SO}_{4}$

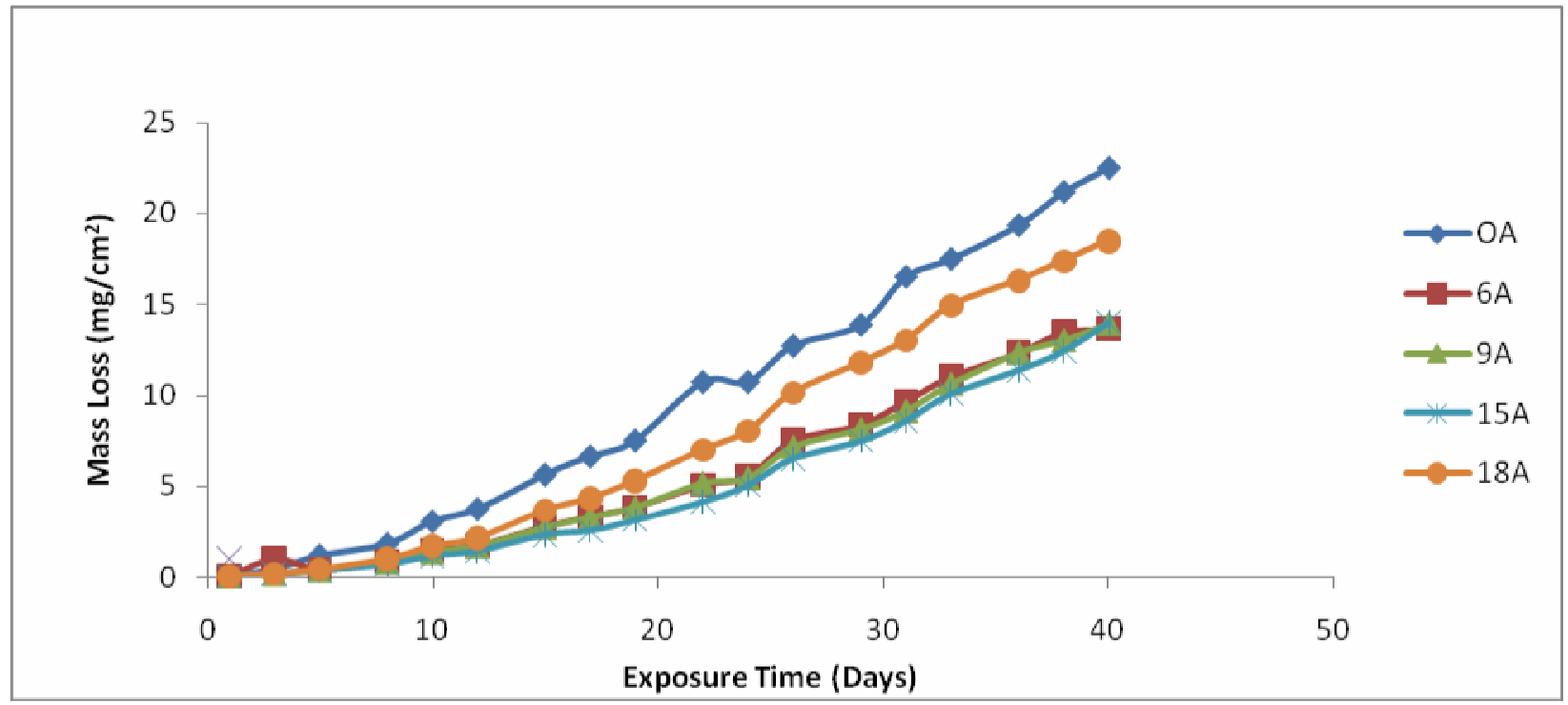

Figure 6b- Variation of corrosion rate of solution-heat treated samples in $\mathrm{H}_{2} \mathrm{SO}_{4}$ 


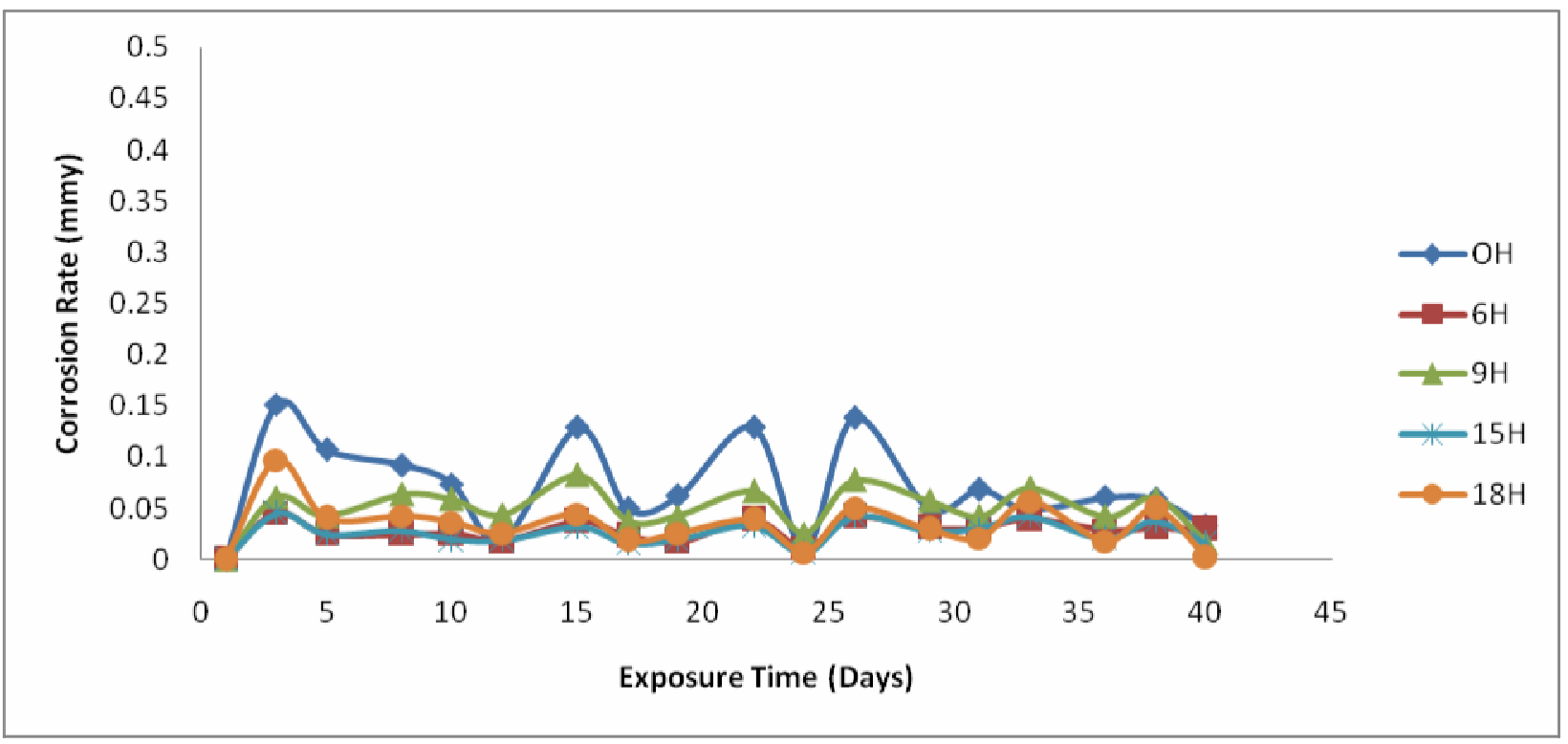

Figure 7a- Variation of mass loss against exposure time of as-cast samples in $\mathrm{H}_{2} \mathrm{SO}_{4}$

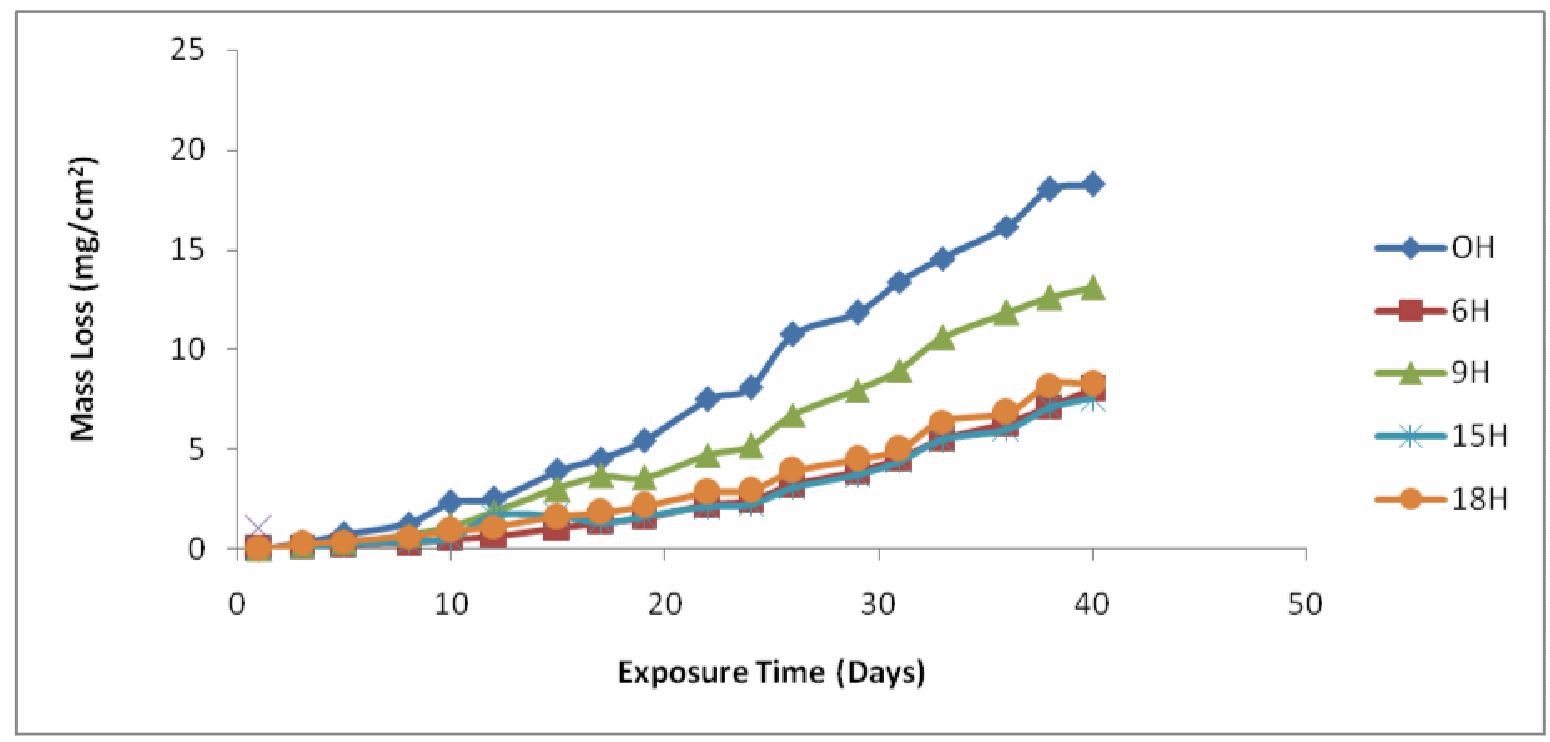

Figure 7b- Variation of mass loss for the solution-heat treated samples in $\mathrm{H}_{2} \mathrm{SO}_{4}$ 


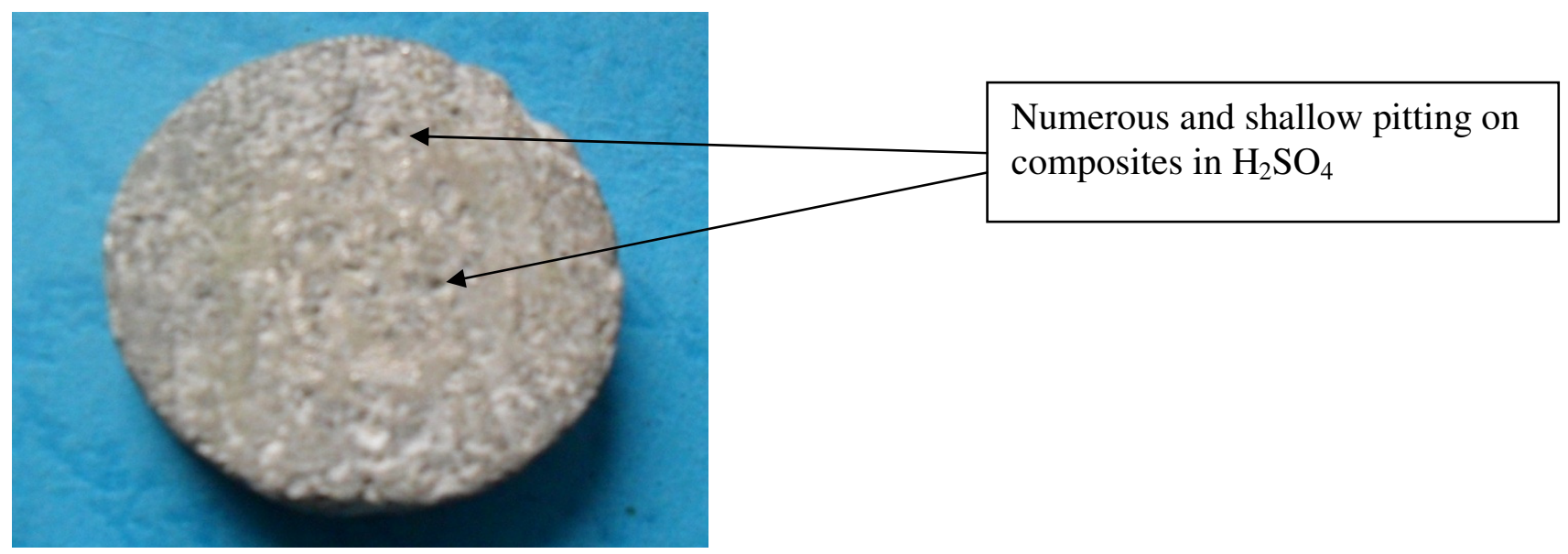

Figure 8a- Corrosion mechanism of $\mathrm{Al}(6063) / \mathrm{Al}_{2} \mathrm{O}_{3 \mathrm{p}}$ composites by pitting in $\mathrm{H}_{2} \mathrm{SO}_{4}$

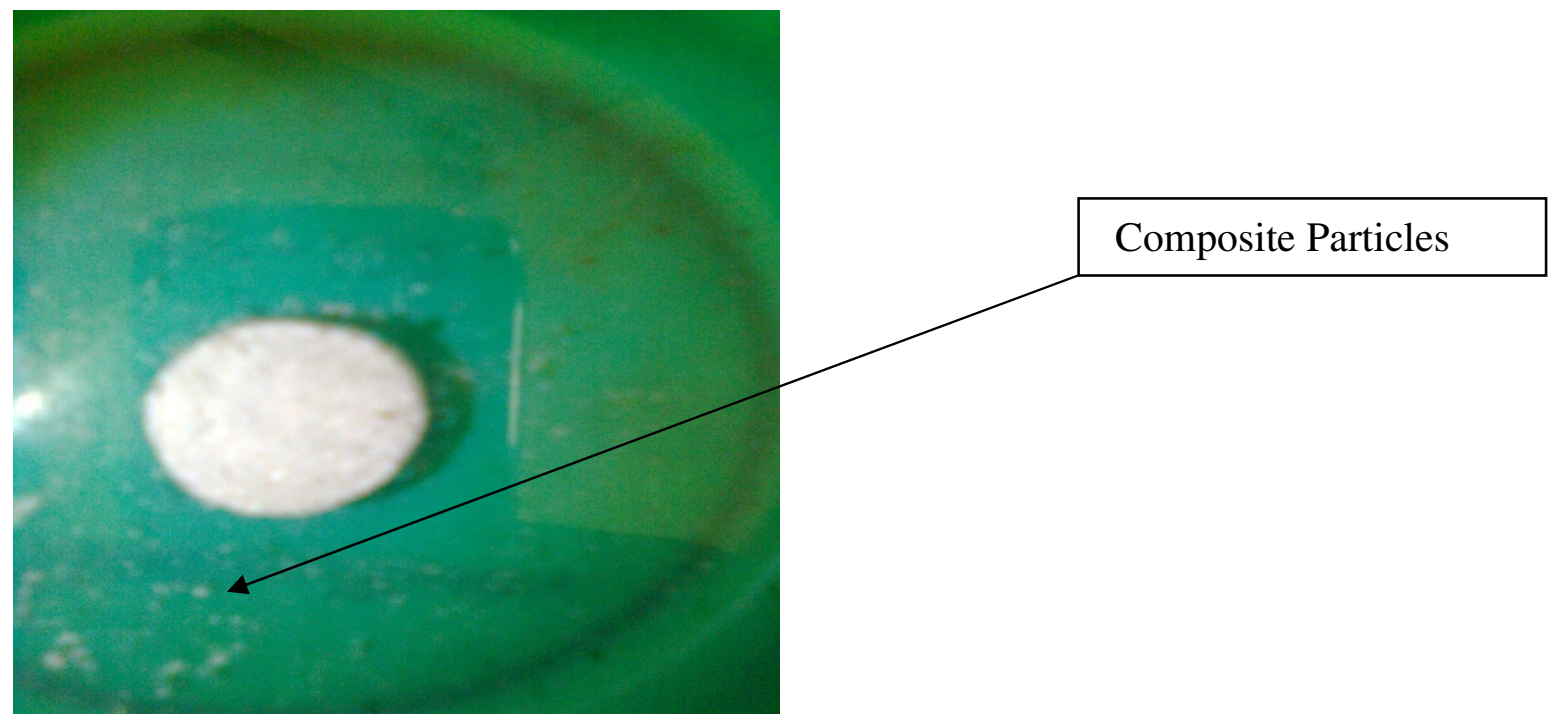

Figure 8b- Metal Dissolution of $\mathrm{Al}(6063) / \mathrm{Al}_{2} \mathrm{O}_{3 \mathrm{p}}$ composites in $\mathrm{H}_{2} \mathrm{SO}_{4}$

\section{CONCLUSION}

In the research work, the corrosion behavior of $\mathrm{AA} 6063 / \mathrm{Al}_{2} \mathrm{O}_{3 \mathrm{p}}$ composite in $\mathrm{NaCl}, \mathrm{NaOH}$ and $\mathrm{H}_{2} \mathrm{SO}_{4}$ was investigated. From the results, it is observed that $\mathrm{Al}(6063)-\mathrm{Al}_{2} \mathrm{O}_{3}$ composites exhibited excellent corrosion resistance in $\mathrm{NaCl}$ medium than in the $\mathrm{NaOH}$ and $\mathrm{H}_{2} \mathrm{SO}_{4}$ media. The unreinforced alloy exhibited slightly superior corrosion resistance than the composites in $\mathrm{NaCl}$ and $\mathrm{NaOH}$ media but the composites had better corrosion resistance in $\mathrm{H}_{2} \mathrm{SO}_{4}$ medium. Furthermore, solution heat-treatment resulted in improved corrosion resistance for both the composites and the unreinforced alloy while the effect of volume percent alumina on corrosion resistance did not follow a consistent trend. 


\section{REFERENCES}

[1] T. A. Khalifa and T. S. Mahmoud, Elevated Temperature Mechanical Properties of Al alloy AA6063/SiC $\mathrm{S}_{\mathrm{p}} \mathrm{MMCs}$, Proceedings of the World Congress on Engineering 2009 Vol II WCE 2009, July 1 - 3, London, U.K, ISBN: 978 -988 -18210-1-0.

[2] M. Adiamak, Selected Properties of Aluminium Base Composite Reinforced with Intermetallic Particles, Journal of Achievement in Materials and Manufacturing Technology, Vol. 14, Issue1-2, 2006, Pp 43-47.

[3] K. R. Ahmad, J. B. Shansul, L.B Hussain and Z. A. Ahmad, The effect of Reinforcement Particle Size on the Microstructure and Hardness of $\mathrm{Al} / \mathrm{Al}_{2} \mathrm{O}_{3}$ Composite via Powder Metallurgy Route 2003, $12^{\text {th }}$ Conference and $13^{\text {th }}$ Annual General Meeting of the Electron Microscopy Society of Malaysia, Langkawi.

[4] V. S. Aigbodion, Particulate Strengthened Al-Si/Alumino-Silicate Composite, Journal of Materials Science and Engineering A, Vol. 460-461, 2007, Pp 574-578.

[5] T. V. Christy, N. Murugan, S. Kumar, Comparative Study on the Microstructure and Mechanical Properties of $\mathrm{Al} 6061 / \mathrm{TiB}_{2} / 12 \mathrm{p}$, Journal of Minerals and Materials Characterization and Engineering, Vol. 9, No.1, 2010, Pp 57-65.

[6] J. S. Kashan, The Effect of Artificial Aging on Mechanical Properties of Metal Matrix Composite, Engineering and Technology Journal, Vol. 28, No. 2, 2010, 282 - 288.

[7] M. Kok, Production and Mechanical Properties of Al2O3 particle reinforced 2024 Aluminium Composites, Journal of Materials Processing Technology, Vol.16, 2005, Pp $381-387$.

[8] G. B. V. Kumar, C. S. P. Rao, N. Selvary, and M. S. Bhagyashekar, Studies on Al7075$\mathrm{Al}_{2} \mathrm{O}_{3}$ Metal Matrix Composites. Journal of Minerals and Materials Characterization and Engineering, Volume 9, No. 1, 2010, Pp 43-45.

[9] O. Omodara and E. C. Onwujiobi, Production and Mechanical Behaviour of Silicon Carbide Reinforced Al (6063) Alloy Particulate Composites, 2010, B.Eng Thesis: Federal University of Technology, Akure, Nigeria.

[10] Y. L. Saraswathi, S. Das, D. P. Mondal, Influence of Microstructure and Experimental Parameters on the Erosion - Corrosion Behaviour of Al (alloy) Composites, Materials Science and Engineering A, 425(2006): $244-254$.

[11] Z. Yussof, K. R. Ahmad, and S. B. Jamaludin, Comparative Study of Corrosion Behavior of AA 2014/15 vol\% $\mathrm{Al}_{2} \mathrm{O}_{3 \mathrm{p}}$ and AA2009/20Vol\% SiCw" Portugaliae Electrochemica Acta, Vol. 26, 2008, pp 291-301.

[12] ASTM Standards, Metals Test Methods and Analytical Procedures, vol. 3.02, Wear and Erosion; Metal Corrosion, G31, 1994, p. 104.

[13] J. Zhu and L. H. Hihara, Corrosion of continuous Alumina-fibre reinforced Al 2wt.\% CuT6 metal matrix composite in 3.15wt.\% NaCl Solution, Corrosion Science, Vol.52, 2010, $406-415$.

[14] M. Tandler, B. Sustarsic, L. Vehovar, Torkar M. Corrosion of Al/SiC Metal-Matrix Composites, Mater Techno, 34(6) (2000) 353 - 358.

[15] P. C. R. Nunes and L. V. Ramanathan, Corrosion behavior of alumina-aluminium and silicon carbide-aluminium metal-matrix composites, Corrosion 51 (1995) 610-617.

[16] D. G. Kolman and Butt, Journal of Electrochemical Society, Vol. 130, No.11, 1997, Pp 3785-3791. 
[17] J. M. G. De-Salazaar, A. Urena, S. Manzabedo, M. I. Barrena, Corrosion Behavior of AA6061 and AA7075 Reinorced with $\mathrm{Al}_{2} \mathrm{O}_{3}$ Particles in Aerated 3.5\% Chloride Solution, Potentiodynamic Measurement and Microstructure Evaluation, Corrosion Science, Volume 41, 1999, pp 529-545.

[18] Abdul-Jameel, H. P. Nagaswararpa, P. V. Krupakara, and T. R. Shashi Shekar, Evaluation of Corrosion Rate of Al6061/ Zircon Metal Matrix Composite in Sea Water, International Journal of Ocean and Oceanography, Vol. 3, No. 1, 2009, pp. 37-42.

[19] L. H. Hihara, Corrosion of Metal Matrix Composite" ASM Handbook Vol. 13B, Corrosion: Materials, S.D Craner and B.S., Covino Jr Ed., ASM International, 2005, pp. 526-524.

[20] Z. M. Gasem and M. Al- Qutub, Corrosion Behavior of Powder Metallurgy Aluminium Alloy 6061/ $\mathrm{Al}_{2} \mathrm{O}_{3}$ Metal Matrix Composite" $6^{\text {th }}$ Saudi Engineering Conference KFUPM, Dhahran, Volume 5, 2008, pp. 270-280.

[21] B. Bobic, S. Mitrovic, M. Bobic, and I. Bobic, Corrosion of Metal Matrix Composites with Aluminium Alloy Substrate, Tribology in Industry, Volume 32, No. 1, 2010, pp. 311. 